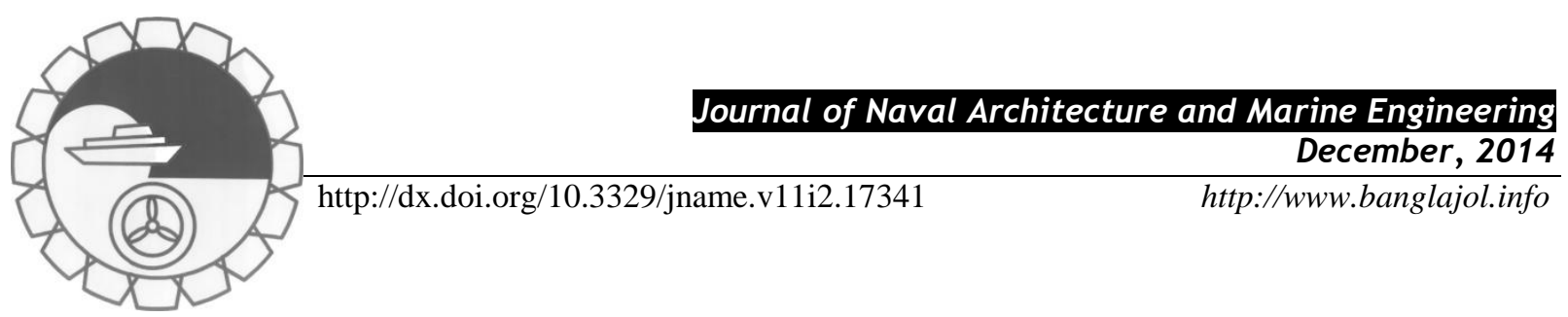

\title{
EXPERIMENTAL INVESTIGATIONS ON TENSION BASED TENSION LEG PLATFORM (TBTLP)
}

\section{S. Bhaskara Rao ${ }^{1}$, R. Panneer Selvam ${ }^{2}$ and Nagan Srinivasan ${ }^{3}$}

${ }^{1}$ Research Scholar, Department of Ocean Engineering, Indian Institute of Technology Madras, Chennai -600036, India, Email: dsbhaskariitm@gmail.com

${ }^{2}$ Corresponding author, Associate Professor, Department of Ocean Engineering, Indian Institute of Technology Madras, Chennai -600036, India, Email: pselvam@iitm.ac.in

${ }^{3}$ Deepwater Structures Inc., Houston, Texas, USA, Email: naganus@ yahoo.com

\begin{abstract}
:
Tension Leg Platforms (TLPS) are one of the reliable structures in the offshore industry in deep waters because of its motion characteristics in heave, roll and pitch degrees of freedom (dof). Heave motion is very important in offshore facilities and have to be kept as minimum as possible. As the water depth increases TLPs suffers from some limitations and hence has to be modified to cater to deeper waters. One such concept proposed is Tension Based Tension Leg Platform (TBTLP). In this paper, experimental investigations carried out on a 1:150 scaled model of a Tension Based Tension Leg Platform in regular waves in $3 \mathrm{~m}$ water depth is reported. These are the first ever experiments which were carried out on a scaled model of the new concept. To investigate the effects of Tension Base, experiments were also conducted on the TLP (without Tension Base). Responses have been compared in terms of Response Amplitude Operators (RAOs) for surge, heave and pitch dof for TBTLP and TLP. Numerical modeling of the TLP and TBTLP responses using ANSYS® AQWA TM software is included as well for comparisons.
\end{abstract}

Keywords: Tension based tension leg platform, model experiment, regular waves, response amplitude operator.

\section{Introduction}

Due to the increase in the demand of oil and gas, offshore exploration has been steadily moving from deep to deeper water depths. For water depths which are greater than $200 \mathrm{~m}$ fixed offshore structures are not economical and compliant structures like Tension Leg Platforms, Articulated Towers, Guyed tower are recommended and further deep waters floating structures like Semi-submersibles, Spars, FPSOs etc. have been adopted by the offshore industries. TLP is a type of complaint type of structure which has excess buoyancy than the weight of the structure. These structures have been connected to the seabed through steel pipes called tethers or tendons and these are always in tension due to excess buoyancy. Schematic view of conventional TLP and degrees of freedom (dof) are shown in Fig. 1 (a). Conventional TLP usually have four columns interconnected with pontoons. Due to pretension in the tendons vertical plane motions (heave, pitch and roll) are almost restrained and almost behave like a fixed platform under normal conditions. TLPs are complaint in horizontal plane motions (surge, sway and yaw). Natural periods in vertical plane motions are less than the daily period wave period range of $5 \mathrm{~s}$ to $30 \mathrm{~s}$ while and horizontal plane motions are beyond this range. But there are some limitations if water depth increases. As the water depth increases, the tendon weight increases and vertical stiffness due to tethers decrease; to maintain buoyancy and weight requirements, vessel size should be increased at the free water surface. To use the TLP concept to deeper waters, researchers proposed modified TLP concepts such as Mini TLPs (Kibbee, 1996), Extended TLP (John., et al., 2009), Suspended TLP (Jagannadhan, 1992), Raft TLP (Abbott., et al., 1994), and Tension Based TLP (Srinivasan, 1998). Response control measures using tuned mass dampers to control the responses of TLPs have also been attempted (Chandrasekaran et al., 2013) instead of modifying the design. Detailed experimental and numerical investigations were carried out by researchers on the modified concepts. Li et al. (2000) conducted experiments on 1:24 scaled mini TLP model which was proposed for marginal fields in China sea at a water depth of $120 \mathrm{~m}$. Niedzwecki et al. (2001) conducted an experimental study on a four-column mini TLP with $10320 \mathrm{t}$ displacement on two scaled models, 1:62 and 1:40 under regular and directional waves. Sreekumar (2001) performed a numerical study to predict coupled dynamics of Seastar mini TLP using Morison type wave loading at two water depths namely $215 \mathrm{~m}$ and $1000 \mathrm{~m}$. Experimental investigations were performed on a 1:50 scaled model corresponding to $215 \mathrm{~m}$ water 
depth for validation of the numerical model. RAO's of the Seastar at two water depths were compared to highlight the limitations associated with the experimental investigations while indicating the influence of water depth on the response of TLPs. Joseph et al. ( 2009) conducted experiments on 1: 56 scale model of 3 leg mini TLP special attention to hull-tether coupling. Measured responses were compared with numerical studies. Comparisons were also made with 4 leg mini TLP to highlight the 3 leg mini TLP.

Tension Based Tension Leg Platform (TBTLP) has been widely discussed by Nagan (1995), Srinivasan (1998), Nagan $(2010,2011)$. This structure has been studied numerically using ANSYS $\AA$ AQWA ${ }^{\mathrm{TM}}$ software (Bhaskara Rao., et al., 2012). TBTLP works on the principle of the inverted double pendulum and uses the Tension Base which is a stiffened box structure whereupon the TLP is mounted. By using this concept a TLP which is designed for lower water depths can be extended to higher water depths. The schematic view of TBTLP shown in Fig. 1 (b). In this paper, the first ever experimental investigations carried out on a TBTLP is reported. Experiments were carried out on the TBTLP and a corresponding TLP without Tension Base and the responses are compared in terms of Response Amplitude Operators. Numerical results carried out are also included for comparisons without elaborating on the simulation details.

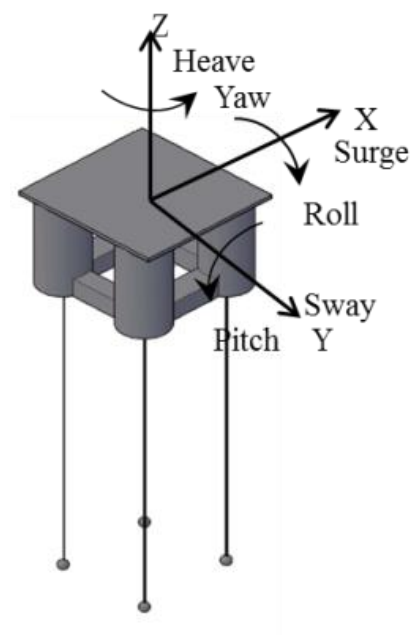

(a)

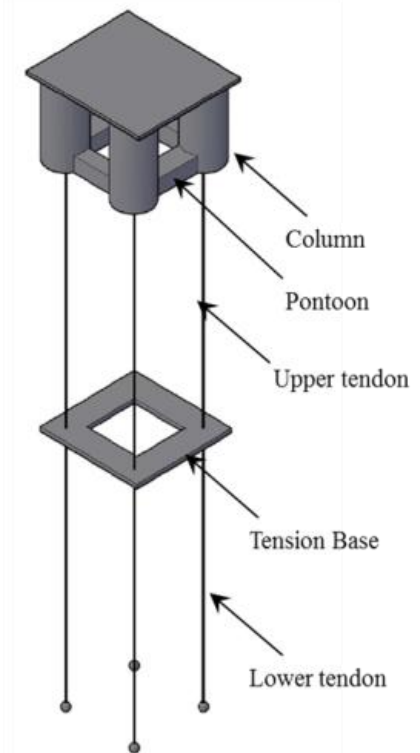

(b)

Fig. 1: Schematic view of (a) Conventional TLP (b) Tension Based TLP

\section{Experimental Study}

\subsection{Model Details and Fabrication}

By taking into consideration of wave generating and water depth facilities which are available at Department of Ocean Engineering, IIT Madras, India, a 1:150 scale model has been chosen for experimental study. Scaling has been carried out by Froude law (Chakrabarti, 1994) and the prototype and model details of TLP are given in Table 1. The TLP consists of four square columns interconnected by a set of trusses at the top and bottom on all the four sides. The geometric details of the TLP model are given in Fig. 2. The prototype Tension Base is a square box of $84 \mathrm{~m} \times 84 \mathrm{~m} \times 3 \mathrm{~m}$ with a provision of a gap in the middle $(40 \mathrm{~m} \times 40 \mathrm{~m} \times 3 \mathrm{~m})$ for the accommodation of risers. The buoyancy to weight ratio of the Tension Base adopted is 1.56. The model was fabricated using Acrylic (density $=1.12 \mathrm{~kg} / \mathrm{m}^{3}$ ). The completed model is shown in Fig. 3 .

\subsection{Details of Tethers and Mooring Lines}

Stainless Steel (SS) wire of $0.45 \mathrm{~mm}$ (upper tendons and mooring lines) and SS wire of $0.6 \mathrm{~mm}$ (lower tendons) were used for connecting the TLP, Tension Base to one another and to the floor. The mooring lines were used to minimize the motions of the Tension Base. All the SS wires were tested in the laboratory to ascertain their engineering properties. The axial stiffness EA of the tendons was determined by a tension test using $500 \mathrm{~mm}$ 
long samples in an UTM. From tension test the axial rigidity (EA) has been obtained as $6.68 \times 10^{3} \mathrm{~N}$ for upper tendons. A schematic diagram of the model with tendons and mooring lines is shown in Fig. 4

Table 1: Details of TLP

\begin{tabular}{|l|l|l|}
\hline Parameter & Prototype & $\mathbf{1 : 1 5 0 ~ m o d e l ~}$ \\
\hline Displacement $(\Delta)$ & $58964 \mathrm{t}$ & $17.45 \mathrm{~kg}$ \\
\hline Total tether pretension $(\mathrm{T}=\Delta-\mathrm{W})$ & $21782 \mathrm{t}$ & $6.45 \mathrm{~kg}$ \\
\hline Weight (including payload) $(\mathrm{W})$ & $37182 \mathrm{t}$ & $11.00 \mathrm{~kg}$ \\
\hline Water depth $(\mathrm{d})$ & $450 \mathrm{~m}$ & $3000 \mathrm{~mm}$ \\
\hline Draft $(\mathrm{D})$ & $31 \mathrm{~m}$ & $207 \mathrm{~mm}$ \\
\hline Height of column & $56 \mathrm{~m}$ & $373 \mathrm{~mm}$ \\
\hline Size of column & $21 \times 21 \mathrm{~m}$ & $140 \mathrm{~mm} \times 140 \mathrm{~mm}$ \\
\hline Length of the tether $(\mathrm{L})$ & $419 \mathrm{~m}$ & $2.79 \mathrm{~m}$ \\
\hline Water plane area $\left(\mathrm{A}_{\mathrm{wp}}\right)$ & $1764 \mathrm{~m}^{2}$ & $78400 \mathrm{~mm}$ \\
\hline Second moment of area of water plane $\left(\mathrm{I}_{\mathrm{wp}}\right)$ & $1.66 \times 10^{6} \mathrm{~m}^{4}$ & $3.273 \times 10^{9} \mathrm{~mm}$ \\
\hline Vertical centre of buoyancy $(\mathrm{VCB})$ & $15.18 \mathrm{~m}$ & $101.2 \mathrm{~mm}$ \\
\hline Vertical centre of gravity $(\mathrm{VCG})$ & $41.65 \mathrm{~m}$ & $278 \mathrm{~mm}$ \\
\hline Mass moment of inertia , $\mathrm{I}_{\mathrm{xx}}$ & $1.53 \times 10^{10} \mathrm{~kg} \cdot \mathrm{m}^{2}$ & $1.93 \times 10^{5} \mathrm{~kg} \cdot \mathrm{mm}{ }^{2}$ \\
\hline Mass moment of inertia, $\mathrm{I}_{\mathrm{yy}}$ & $1.62 \times 10^{10} \mathrm{~kg} \cdot \mathrm{m}^{2}$ & $2.06 \times 10^{5} \mathrm{~kg} \cdot \mathrm{mm}{ }^{2}$ \\
\hline Mass moment of inertia , $\mathrm{z}_{\mathrm{zz}}$ & $2.74 \times 10^{10} \mathrm{~kg} \cdot \mathrm{m}^{2}$ & $3.33 \times 10^{5} \mathrm{~kg} \cdot \mathrm{mm}{ }^{2}$ \\
\hline Total tether stiffness $(4 \mathrm{AE} / \mathrm{L})$ & $2.15 \times 10^{8} \mathrm{~N} / \mathrm{m}$ & $9.56 \times 10^{3} \mathrm{~N} / \mathrm{m}$ \\
\hline
\end{tabular}

For model tether: E (Young's modulus) $=4.2 \times 10^{10} \mathrm{~N} / \mathrm{m}^{2}$

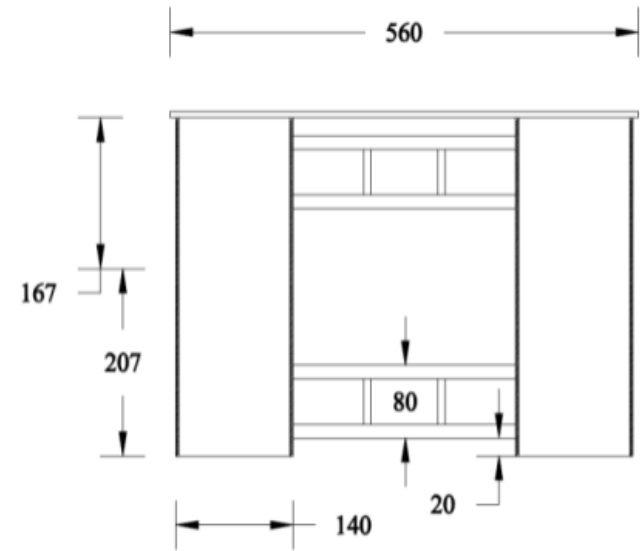

$\mathrm{A}($ cross section area $)=1.59 \times 10^{-7} \mathrm{~m}^{2}$

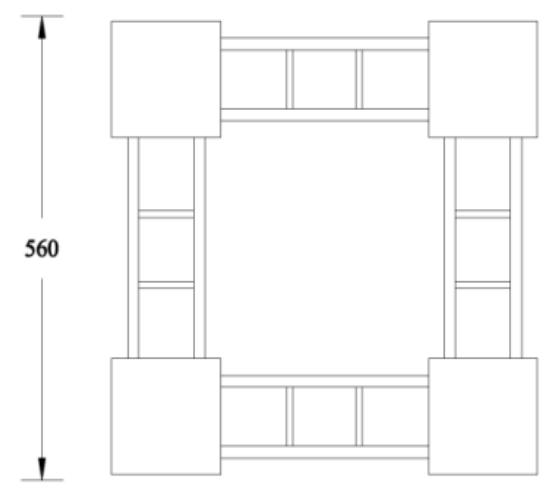

Fig. 2: Geometric details of TLP 


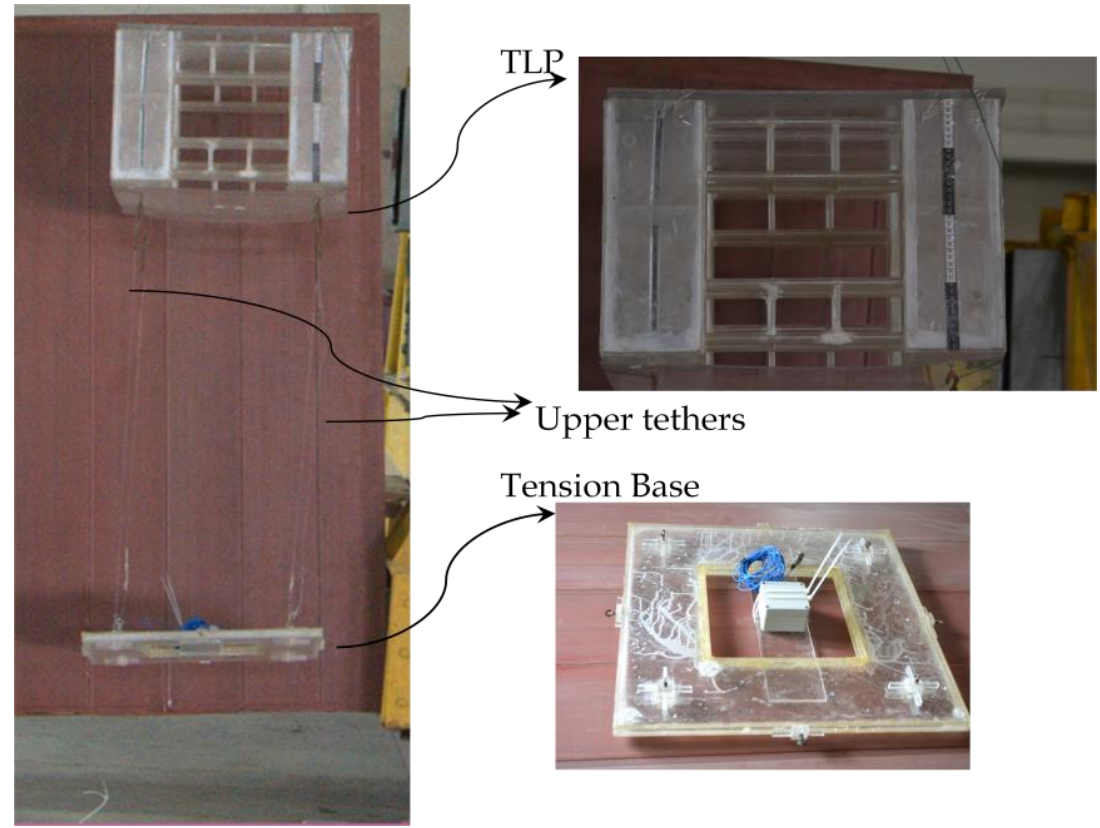

Fig. 3: TBTLP model in air

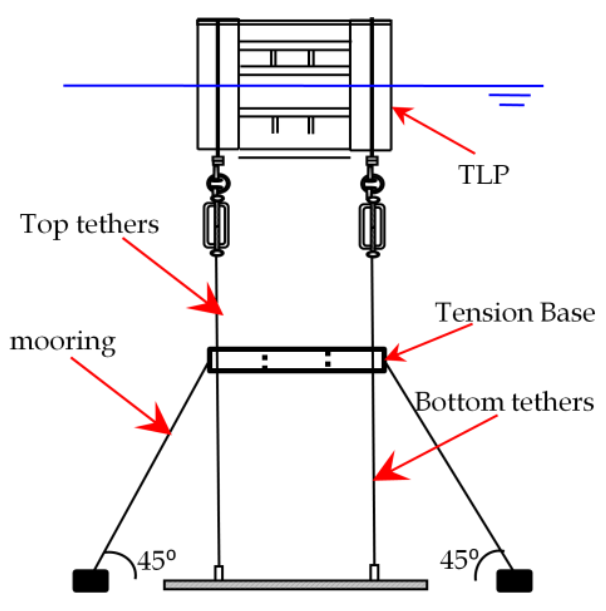

Fig. 4: Schematic view of TBTLP with tethers and mooring lines

\subsection{Instrumentation}

The water surface elevation was measured by means of wave probes. The principle of varying conductivity with immersion of electrodes is applied in the wave probe for measurement. The electrodes are housed in a slim, streamline plastic profile with stainless steel armoring. The probe was mounted on a support and can be fixed at any required depth. The wave probe was calibrated by vertically raising and lowering in known incremental distances relative to the still water level and recording the corresponding analog output voltage from the wave amplifiers. To measure the incident wave, one wave probe was fixed at a distance of $6 \mathrm{~m}$ ahead of the model; second wave probe was fixed parallel to the axis of the structure at a distance of $5 \mathrm{~m}$. Phase lag of the responses can be found using the time series of the incident wave of the second wave probe. Inductive, single axis accelerometers (weight $=17 \mathrm{~g}$ ) with natural frequency of $200 \mathrm{~Hz}$ and measuring range of $100 \mathrm{~Hz}$ were used. MGC55 carrier frequency amplifiers were used for signal amplification. Two accelerometers were fixed on top of the deck to measure vessel accelerations in surge and heave. Inclinometer was used to measure the pitch response of the model. An accelerometer was made water proof by using a sealed box and this was used to measure the surge response of Tension Base. The complete experimental setup is shown in Fig. 5. 


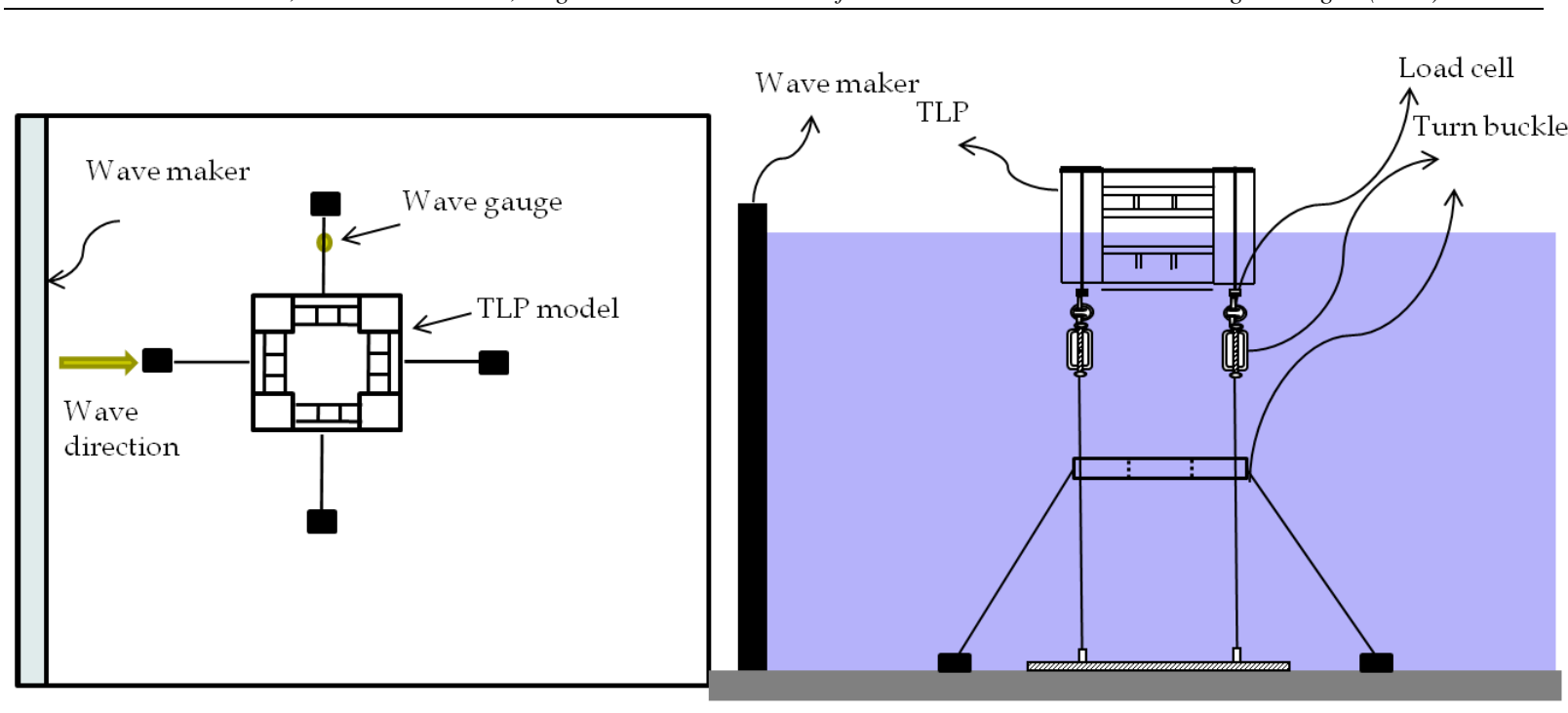

Fig. 5: Experimental set up (Schematic view)

\subsection{Wave Parameters}

A 100 year wave in the Gulf of Mexico (GoM) waters has been chosen as a design wave, which has significant wave height of $15.8 \mathrm{~m}$ and peak period $15.2 \mathrm{~s}$. For this sea state significant range of periods are from $7.5 \mathrm{~s}$ to 24 $\mathrm{s}$. The scaled model has been tested under regular waves with wave height range $2-10 \mathrm{~cm}$ and wave period ranging from $0.67 \mathrm{~s}$ to $2.5 \mathrm{~s}$ in model scale, which corresponds to $8.16 \mathrm{~s}-30.62 \mathrm{~s}$ in prototype and covers the most significant range of periods. The wave steepness range is 0.002 to 0.01 . In most cases the results of $\mathrm{H}=4$ $\mathrm{cm}$ are presented in arriving at the Response Amplitude Operators (RAOs)

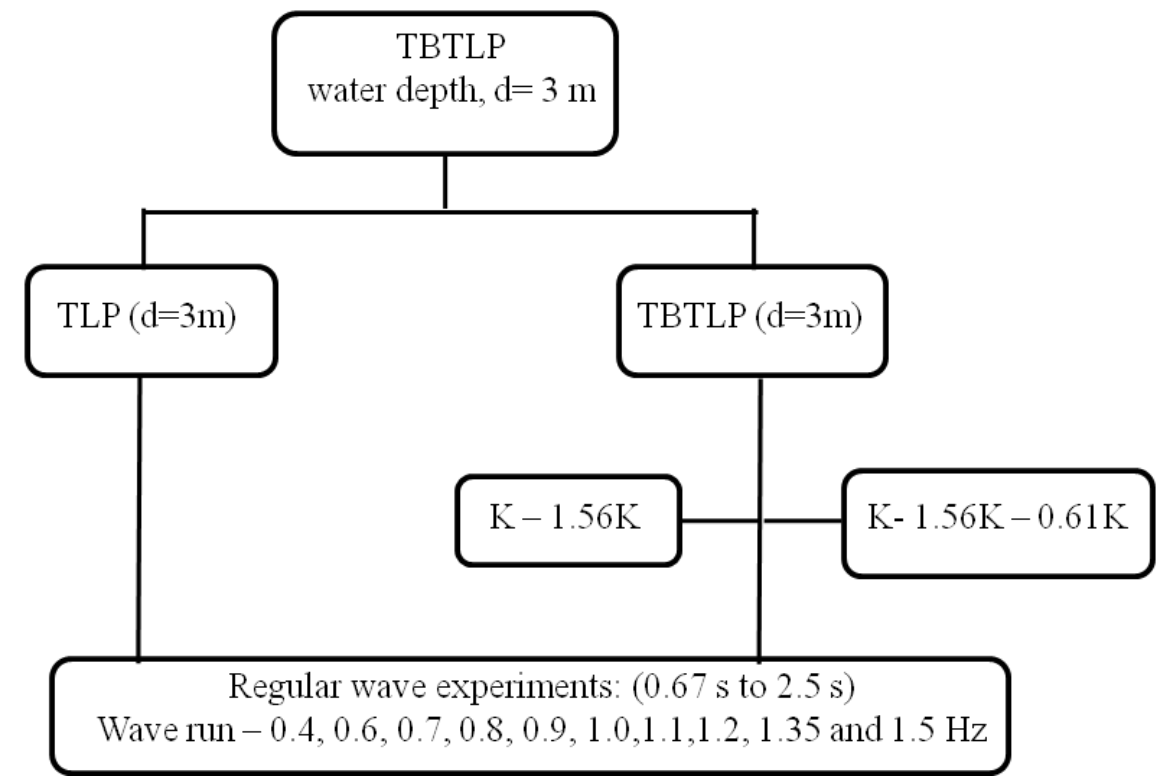

Fig. 6: Flowchart of test cases

$\mathrm{K}-1.56 \mathrm{~K}$ : Bottom tethers are $156 \%$ stiffer than top tethers; $\mathrm{K}-1.56 \mathrm{~K}-0.61 \mathrm{~K}$ : Bottom tethers are $156 \%$ stiffer than top tethers and the mooring lines stiffness for Tension Base are $61 \%$ that of top tether stiffness .

\subsection{Test Cases}

Experiments were conducted for the following cases:

Case 1: TLP at a water depth of $3 \mathrm{~m}$ (Prototype water depth $450 \mathrm{~m}$ ). 
Case 2: TBTLP at a water depth of $3 \mathrm{~m}$ (Prototype water depth of $450 \mathrm{~m}$ ), position of Tension Base is at $1.5 \mathrm{~m}$ (prototype water depth $225 \mathrm{~m}$ ). The ratio of bottom tether stiffness to upper adopted was $1.56(\mathrm{~K}-1.56 \mathrm{~K})$.

Case 3: TBTLP at a water depth of $3 \mathrm{~m}$ (Prototype water depth of $450 \mathrm{~m}$ ), position of Tension Base is at $1.5 \mathrm{~m}$ (prototype water depth $225 \mathrm{~m}$ ) with $45^{\circ}$ taut moorings for Tension Base. The ratio of mooring line stiffness to top tethers adopted was $0.61(\mathrm{~K}-1.56 \mathrm{~K}-0.61 \mathrm{~K})$. Fig. 6 gives the flowchart of the test cases.

\subsection{Wave Basin and Experimental Set-up}

Experiments were conducted in the wave basin at Department of Ocean Engineering, IIT Madras, India. The wave basin has a constant water depth of $3 \mathrm{~m}$ and is square in plan of $30 \mathrm{~m} \times 30 \mathrm{~m}$. It is equipped with the stateof-the-art Multi-Element Wave Maker (MEWM) at one end and Long Crested Wave Maker (LCWM) at another side. The photograph of the wave basin at Indian Institute of Technology, Madras is shown in Fig. 7. The MEWM is capable of generating waves with or without directional spreading, referred to as three dimensional (3D) and two dimensional (2D) waves respectively. The MEWM consist of 52 paddles, each of $0.5 \mathrm{~m}$ wide and hinged to a platform, which is $1.7 \mathrm{~m}$ above the basin floor. The digital servo controllers (DSC) perform the servo control of the wave maker motions. The LCWM is capable of generating regular and random long crested waves. The wave absorber is formed by placing, wooden sleepers at a curved slope.

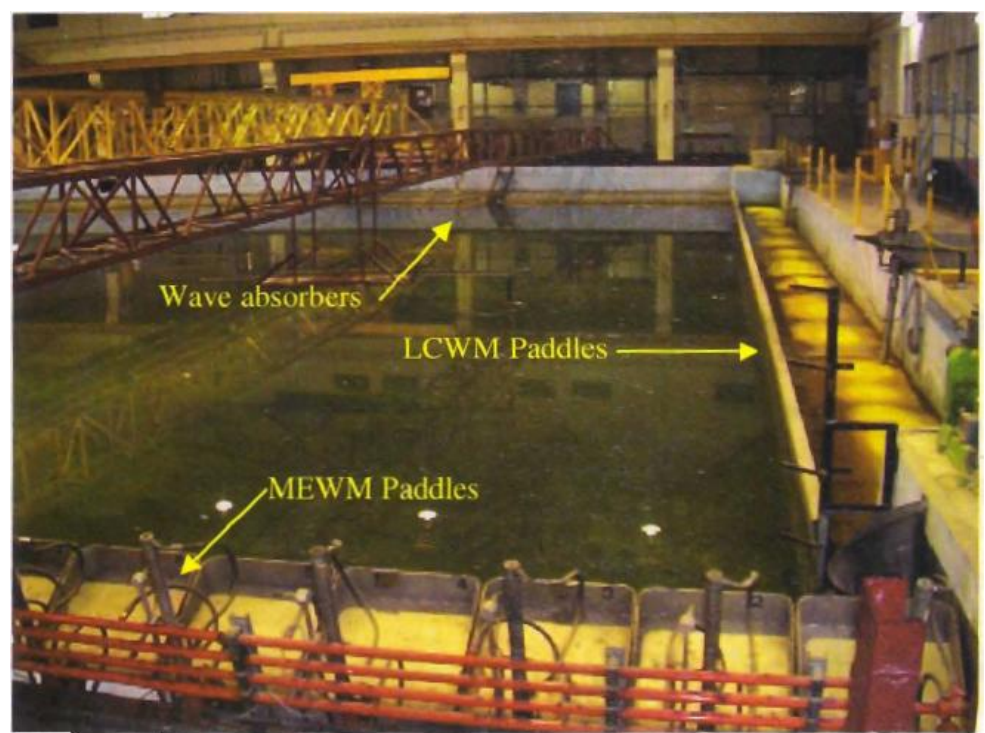

Fig. 7: Wave basin at Indian institute of Technology Madras, India

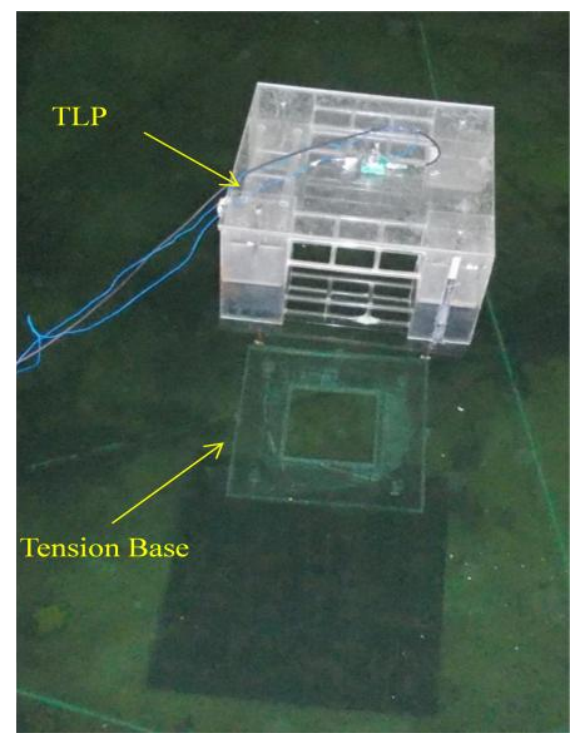

Fig. 8: Completed TBTLP Model in wave basin

In the present experimental investigation, the TLP and TBTLP models were placed at a distance of $10 \mathrm{~m}$ away from the MEWM. The position was carefully chosen so as to avoid any reflections and interference of waves between the model and the wave maker. It was also ensured that the reflected waves from the wave beach (farther end of the wave basin) were minimal. Three accelerometers were fixed on the model to measure the response of the model. One wave probe was placed away from the model to measure the incident wave. The mooring lines were connected to the model and anchored using concrete blocks. The depth of the water was kept at $3.0 \mathrm{~m}$. A schematic diagram of the complete experimental set up is shown in Fig. 5 and a photograph of complete model in wave basin is shown in Fig. 8.

Free oscillation test and regular wave test for the cases given in Flowchart (see Fig. 6) matrix were performed on the model. The different cases of experiments are discussed in the following sections.

\subsection{Free Decay Tests}

Free oscillation tests were conducted in still water in the surge and heave dof to obtain their respective natural periods and damping ratios. The surge oscillation test was done by giving a horizontal displacement of the vessel which was tethered condition in still water and the resulting horizontal motion of the vessel was recorded till decay. The heave oscillation test was done by giving a vertical downward displacement at the centre of the 
vessel which was in tethered condition in still water and the resulting vertical motion of the vessel was recorded till decay. Accelerations were recorded for surge, heave dof. Displacements have been obtained by integration. From these free oscillation test time series natural period and the damping ratio in the surge and heave motions were estimated using logarithmic decrement method. The natural period of the Tension Base has an effect on the response of the surface structure (TLP). Free decay tests were also conducted for Tension Base in surge dof. Free decay time series for TLP and Tension Base are shown in Fig. 9.

\subsection{Regular Wave Experiments}

Regular wave tests were conducted and responses were recorded in surge and heave dof for wave frequencies shown in the flowchart (Fig. 6). Sample time history recorded for a wave frequency of $0.7 \mathrm{~Hz}$ is shown in Fig. 10. Motion responses were reported in terms of transfer functions (RAOs) for surge, heave and pitch motions. RAOs are obtained by dividing the wave amplitude with the corresponding response amplitude.

\section{Numerical Analysis}

ANSYS ${ }^{\circledR}$ AQWA ${ }^{\mathrm{TM}}$ (Ansys Inc., 2010) is a hydrodynamic package by which the hydrodynamic responses of floating structures like TLPs, Semi submersibles, Spar, etc., in regular and irregular waves, including the effect of moorings can be obtained in time domain or in the frequency domain. It is an integrated suite of analysis programs for fixed, floating and compliant offshore structures. In this, the diffracting structures and drag dominated structures can be modeled using line and disc elements representing the vessel or structure and the cable elements to represent the moorings or risers. The hydrodynamic analysis includes generation of a line model of the structure using ANSYS Workbench, calculation of motion response amplitude operators (RAOs) in the free floating mode using AQWA-LINE, calculation of the Eigen values of the structure in tethered condition at equilibrium position using AQWA-LIBRIUM and simulation of motion responses in the time domain in tethered mode using the AQWA-NAUT under regular and irregular waves. Various parameters describing the body, wave details besides water depth have to be given as inputs and results in terms of responses in time/frequency domain can be obtained. There are no other boundary conditions are normally needed for the analysis, unlike Computation Fluid Dynamic or Finite Element based software. As per the document of ANSYS ${ }^{\circledR}$ AQWA ${ }^{\mathrm{TM}}$ there are no known issues or limitations of the software. (ANSYS, Inc., 2011). However,

Case 2: TLP

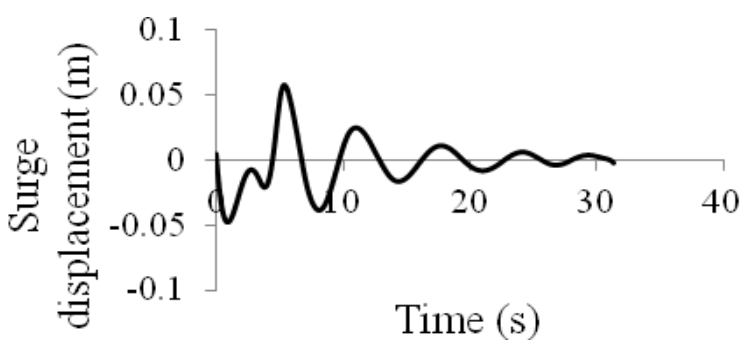

Case 3: TLP

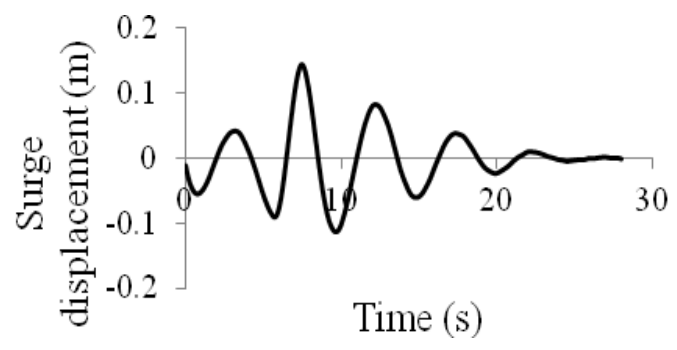

Case 2: TB

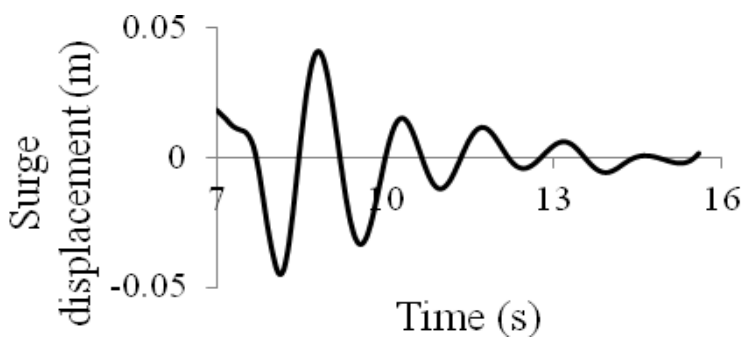

Case 3: TB

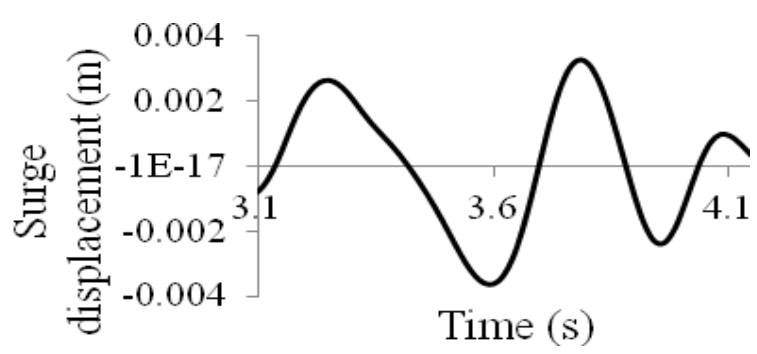

Fig. 9: Measured free decay time series Case 2: (a) TLP surge, (b) TB surge, Case 3: (c) TLP surge (d) TB surge 

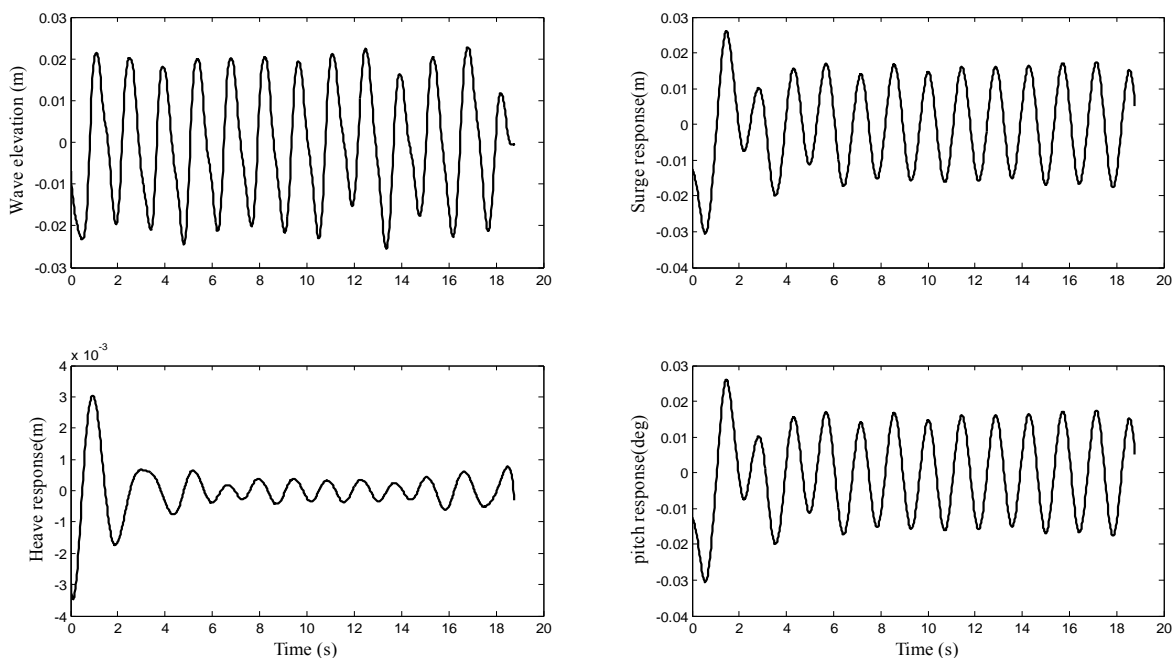

Fig. 10: Time record sample for $0.7 \mathrm{~Hz}$ and $\mathrm{H}=4 \mathrm{~cm}$ (Case 1)

there are limitations of correct modeling of damping parameters, especially the viscous damping effects and damping values are to be suitably incorporated to obtain reasonable results that can be compared with those from experiments or full scale measurements.

\section{Results and Discussion}

\subsection{Free Decay Tests}

Natural periods and damping ratios obtained for different cases are tabulated in Table 3 for surge and heave dof. Tension Base surge natural periods are given in Table 4. Natural periods obtained from experiments are scaled to prototype for better comparison with the numerical results. With the provision of mooring for Tension Base natural period in surge reduces from $1.46 \mathrm{~s}$ to $0.34 \mathrm{~s}$ (prototype $17.88 \mathrm{~s}$ to $4.2 \mathrm{~s}$ ) and for TLP, it reduces from $6.19 \mathrm{~s}$ to $4.86 \mathrm{~s}$ (prototype $75.81 \mathrm{~s}$ to $59.52 \mathrm{~s}$ ).

Table 3: Natural period and damping ratios for different Cases

\begin{tabular}{|l|c|c|c|c|c|c|c|c|}
\hline & \multicolumn{4}{|c|}{ Surge } & \multicolumn{4}{c|}{ Heave } \\
\hline Case & $\begin{array}{c}\mathbf{T}_{\mathbf{n}} \\
(\mathbf{s})\end{array}$ & $\begin{array}{c}\boldsymbol{\xi} \\
(\boldsymbol{\%})\end{array}$ & $\begin{array}{c}\text { Prototype } \\
\left(\mathbf{T}_{\mathbf{n}}\right) \\
(\mathbf{s})\end{array}$ & $\begin{array}{c}\text { Numerical } \\
(\mathbf{s})\end{array}$ & $\begin{array}{c}\mathbf{T}_{\mathbf{n}} \\
(\mathbf{s})\end{array}$ & $\begin{array}{c}\xi \\
(\boldsymbol{\%})\end{array}$ & $\begin{array}{c}\text { Prototype } \\
(\mathbf{T N}) \\
(\mathbf{s})\end{array}$ & $\begin{array}{c}\text { Numerical } \\
(\mathbf{s})\end{array}$ \\
\hline TLP_450 m & 7.07 & 2.25 & 86.59 & 85.56 & 0.18 & 2.40 & 2.20 & 2.50 \\
\hline TBTLP $(\mathrm{K}-1.56 \mathrm{~K})$ & 6.19 & 5.12 & 75.81 & 83.33 & 0.22 & 2.80 & 2.69 & 2.90 \\
\hline TBTLP $(\mathrm{K}-1.56 \mathrm{~K}-0.61 \mathrm{~K})$ & 4.86 & 5.65 & 59.52 & 59.63 & 0.22 & 4.62 & 2.69 & 2.83 \\
\hline
\end{tabular}

Table 4: Surge Natural period and damping ratios for TB

\begin{tabular}{|l|l|l|l|l|}
\hline Case & $\mathbf{T}_{\mathbf{n}}(\mathbf{s})$ & $\boldsymbol{\xi}(\%)$ & Pototype $\left(\mathbf{T}_{\mathbf{n}}\right)(\mathbf{s})$ & Numerical $(\mathbf{s})$ \\
\hline TB(K $-1.56 \mathrm{~K})$ & 1.46 & 4.75 & 17.88 & 17.3 \\
\hline TBTLP $(\mathrm{K}-1.56 \mathrm{~K}-0.61 \mathrm{~K})$ & 0.34 & 6.93 & 4.16 & 4.01 \\
\hline
\end{tabular}

\subsection{Motion responses}

The RAOs for TLP and TBTLP with and without Tension Base mooring for surge heave and pitch dof also the Tension Base surge dof as obtained from experiments as well as numerical modeling are shown in Figs. 11-12. The data from the experiments are shown as discrete points and marked 'Exp'. Numerical analysis results are only included for TLP at a water depth of $225 \mathrm{~m}$ due to constraints of carrying out experiments at this depth.

TBTLP without Tension Base mooring 
From Fig. 11 (a), it is observed that the surge RAOs increases as the wave period increases for all the cases. While comparing the surge RAOs of the TLP in two different water depths, it is seen that surge RAO of the TLP do not differ for wave period range of 8 to $15 \mathrm{~s}$. However, beyond wave periods greater than $17 \mathrm{~s}$ the surge RAO is higher for TLP at $225 \mathrm{~m}$ when compared to surge RAO for TLP at $450 \mathrm{~m}$. This is attributed to the tendon nonlinear stiffening effects. The surge RAO of the TBTLP (without mooring of the Tension Base) in $450 \mathrm{~m}$ water depth increases as the wave period increases and do not differ from the surge RAOs of the TLPs for wave period below $14 \mathrm{~s}$. However, beyond $14 \mathrm{~s}$ the surge RAO of the TBTLP decreases with the designed upper and lower tendons. The combined stiffness effects of the upper and lower tendons contribute to a lower surge RAO response. For a wave period of $30 \mathrm{~s}$ the TBTLP surge response is $46 \%$ lower as that of the TLP at $225 \mathrm{~m}$ water depth. The dip near $18 \mathrm{~s}$ is caused due to the resonant effect of the Tension Base, where in the out of phase motions of the Tension Base affects the surge RAO of the TBTLP in this region. The reduction of surge response is in the order of $67 \%$.

From Fig. 11 (b), it is observed that the heave RAOs increases as the wave period increases for TLPs and is less than 0.06, as this dof is stiff. While comparing the heave RAOs of the TLP in two different water depths, it is seen that heave RAO of the TLP in $225 \mathrm{~m}$ are less compared to the heave RAO of $450 \mathrm{~m}$ as expected due to the difference of heave stiffness, which is higher for TLP at $225 \mathrm{~m}$. The heave RAO of the TBTLP (without mooring of the Tension Base) in $450 \mathrm{~m}$ water depth increases as the wave period increases and do not differ from the heave RAOs of the TLP at $225 \mathrm{~m}$ water depth for wave period below $14 \mathrm{~s}$ and beyond $20 \mathrm{~s}$. The TBTLP shows a characteristic behavior near the Tension Base resonant period of $18 \mathrm{~s}$, peaking at this region. This increase observed in experiments is about 300\% when compared to that of the TLP at $450 \mathrm{~m}$ without Tension Base. As this peak is undesirable the Tension Base has been moored to reduce this effect.

The pitch RAOs of TBTLP without mooring are compared with that of the pitch RAOs of the TLP in $450 \mathrm{~m}$ in Fig. 11 (c). The experimental values are less than $2 \% \mathrm{~m}$ for the range of wave periods considered and the numerical model fairly matches the experimental values for the TLP in $450 \mathrm{~m}$ water depth. Considerable deviations are observed in the numerical model of TBTLP without mooring due to incorrect modeling of damping wherein the viscous damping effects are not included.

The interaction effects of Tension Base with the TLP especially the surge and heave coupling of the two systems acting like a double pendulum is a serious concern. This was also observed during the experiments conducted on the model of TBTLP. The surge motion of the Tension Base, shown in Fig. 11 (d), influences the heave motion of the TLP which is reflected in Fig. 11(b). Considerable deviations are observed in the numerical model of surge RAO of Tension Base (see Fig. 11 (d)) without mooring which can be attributed to incorrect modeling of damping.

\section{TBTLP with Tension Base mooring}

From Fig. 12 (a), it is observed that the surge RAOs increases as the wave period increases for all the cases. While comparing the surge RAOs of the TLP in two different water depths, it is seen that surge RAO of the TLP do not differ for wave period range of 8 to $15 \mathrm{~s}$. However, beyond wave periods greater than $15 \mathrm{~s}$ the surge RAO is higher for TLP at $225 \mathrm{~m}$ when compared to surge RAO for TLP at $450 \mathrm{~m}$. This is attributed to the tendon nonlinear stiffening effects. The surge RAO of the TBTLP with mooring of the Tension Base in $450 \mathrm{~m}$ water depth increases as the wave period increases and matches closely to the behavior of TLP at $225 \mathrm{~m}$. The influence of the Tension Base effects observed in the previous case (Tension Base without mooring) has been eliminated due to the provision of mooring lines.

From Fig. 12 (b), it is observed that the heave RAOs increases as the wave period increases for all the cases and is less than 0.06, as this dof is stiff. While comparing the heave RAOs of the TLP in two different water depths, it is seen that heave RAO of the TLP in $225 \mathrm{~m}$ are less compared to the heave RAO of $450 \mathrm{~m}$ as expected due to the difference of heave stiffness, which is higher for TLP at $225 \mathrm{~m}$. The heave RAO of the TBTLP (with mooring of the Tension Base) in $450 \mathrm{~m}$ water depth increases as the wave period increases and are less than that of the TLP at $450 \mathrm{~m}$ water depth without Tension Base but higher than that of the TLP at $225 \mathrm{~m}$ water depth. From Figs. 11 (b) and 12 (b) the role played by the mooring line of the Tension Base is clearly evident. 


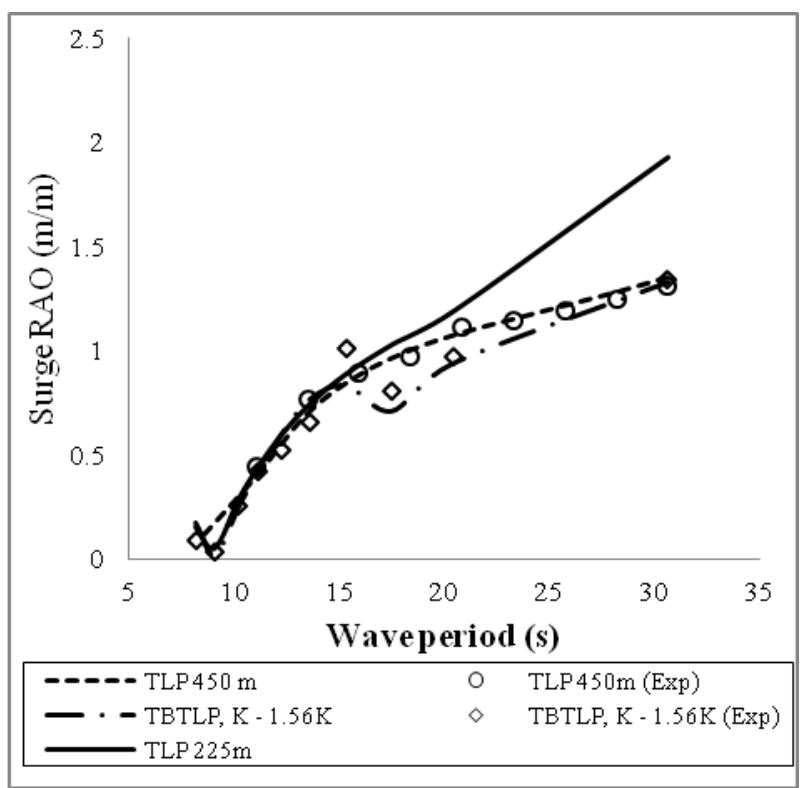

(a)

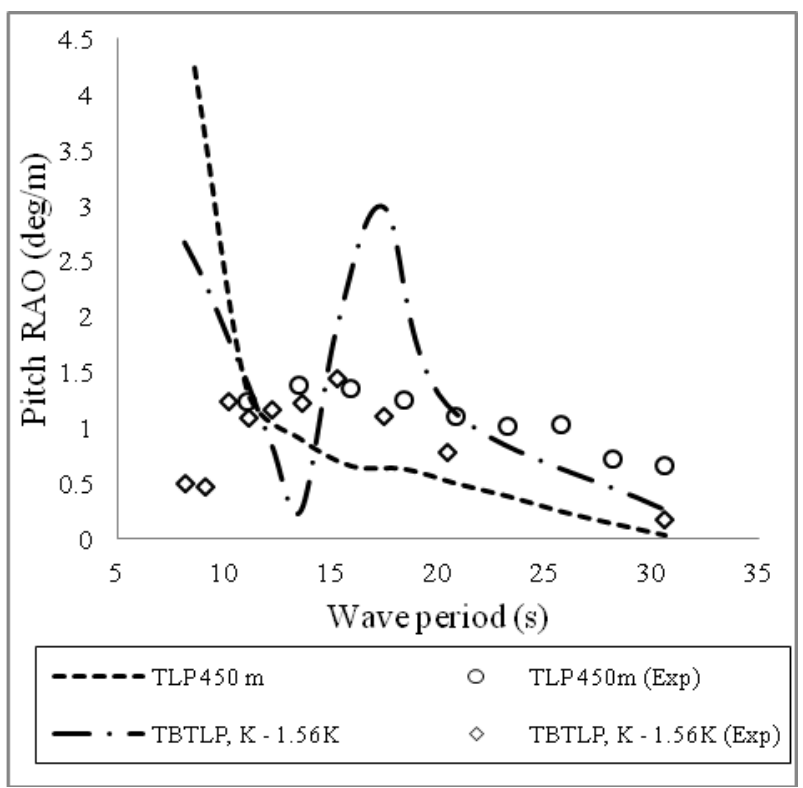

(c)

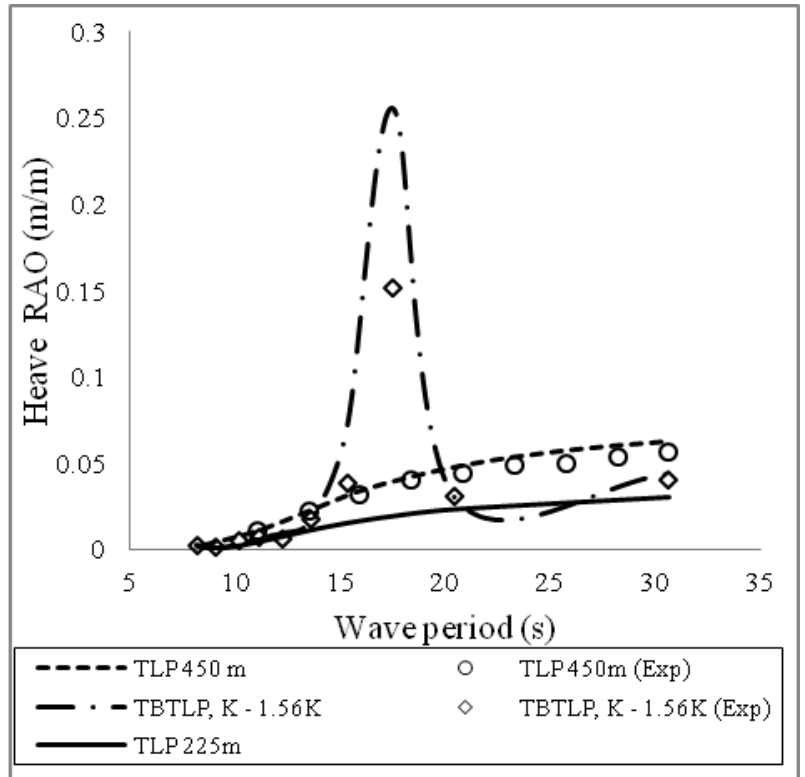

(b)

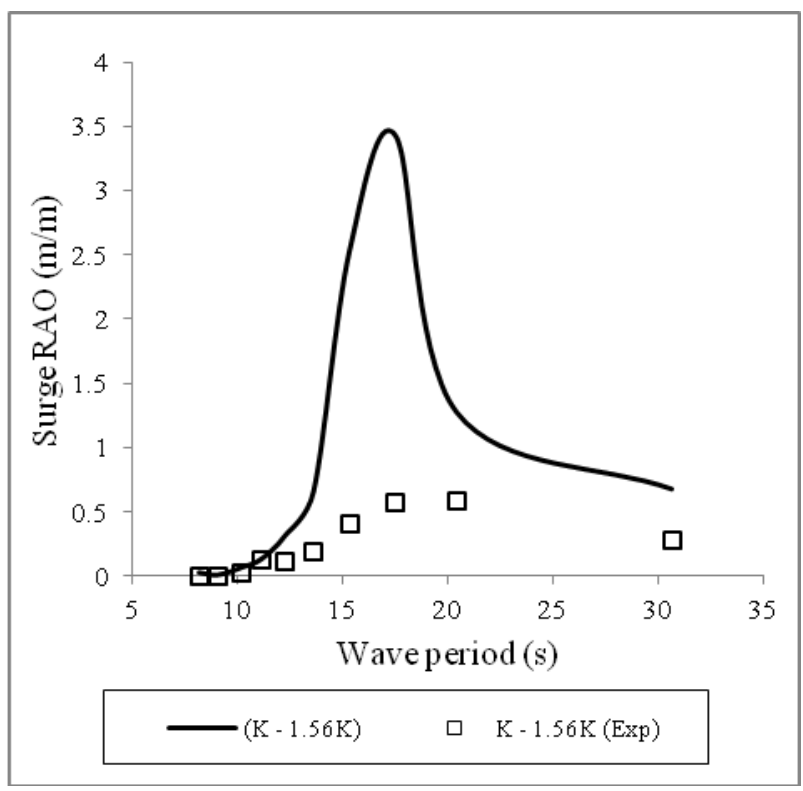

(d)

Fig. 11:. Comparison of RAOs for TLP and TBTLP (without mooring to TB) (a) Surge RAO (b) Heave RAO (c) pitch RAO (d) TB - surge RAO

The pitch RAOs of TBTLP with mooring are compared with that of the pitch RAOs of the TLP in $450 \mathrm{~m}$ in Fig. 12 (c). The experimental values are less than $1.5 \% \mathrm{~m}$ for the range of wave periods considered and the numerical model fairly matches the experimental values for the TLP in $450 \mathrm{~m}$ water depth.

Tension Base surge RAOs are given in the Figs. 11 (d) and 12 (d) for the cases without and with mooring respectively. As observed from Figs. 11 (b), (d) and 12 (b), (d), by the provision of mooring the response of Tension Base has been drastically reduced there by, the coupled motions of TLP with Tension Base have also been reduced. 


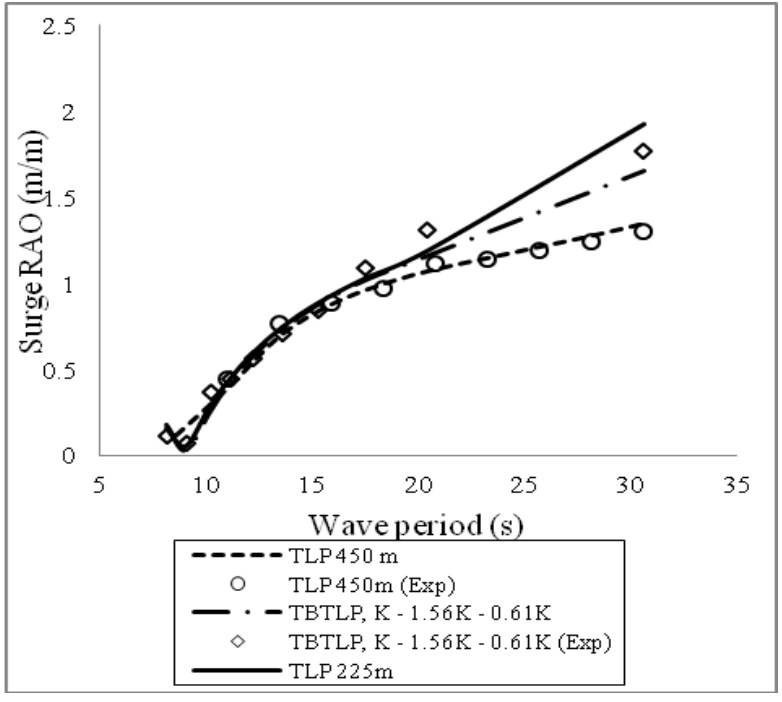

(a)

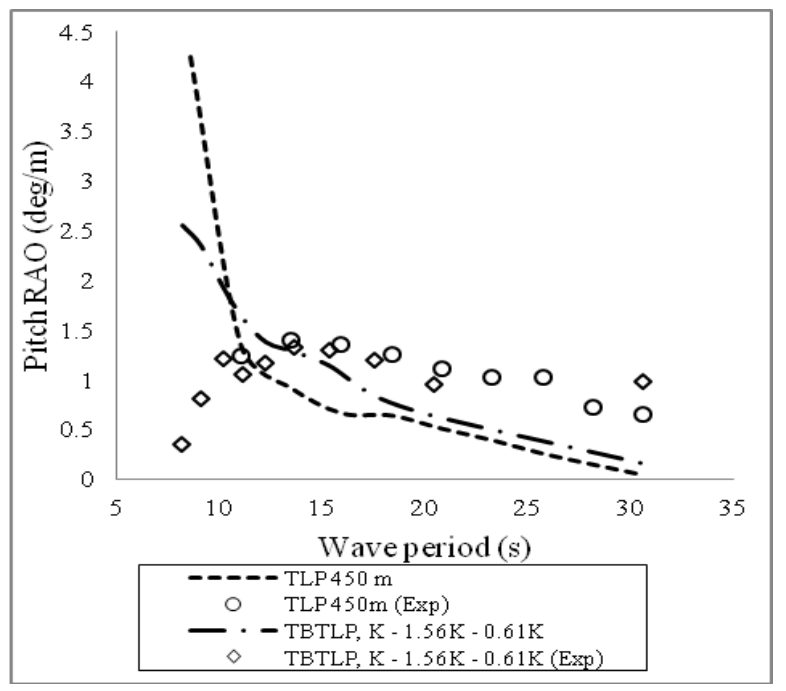

(c)

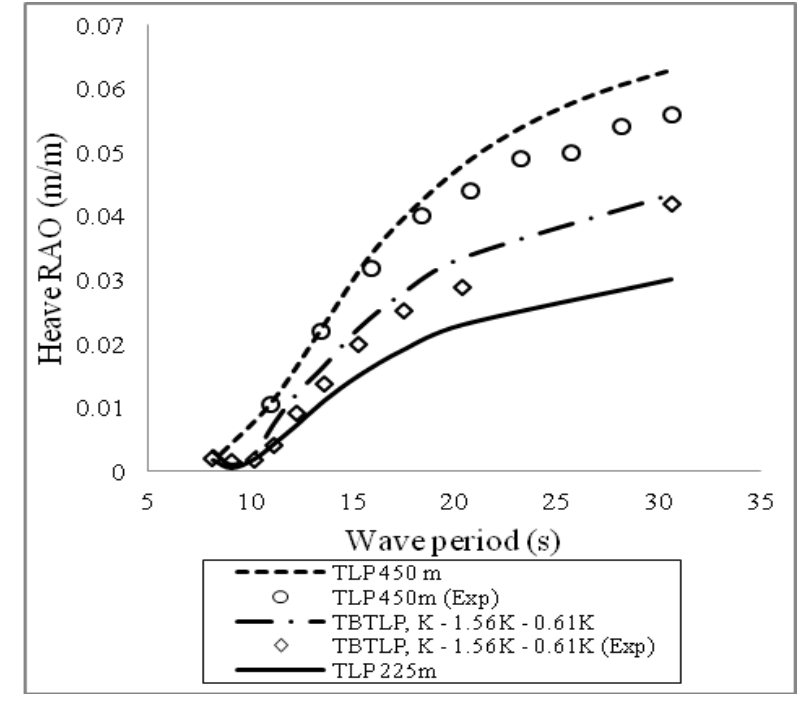

(b)

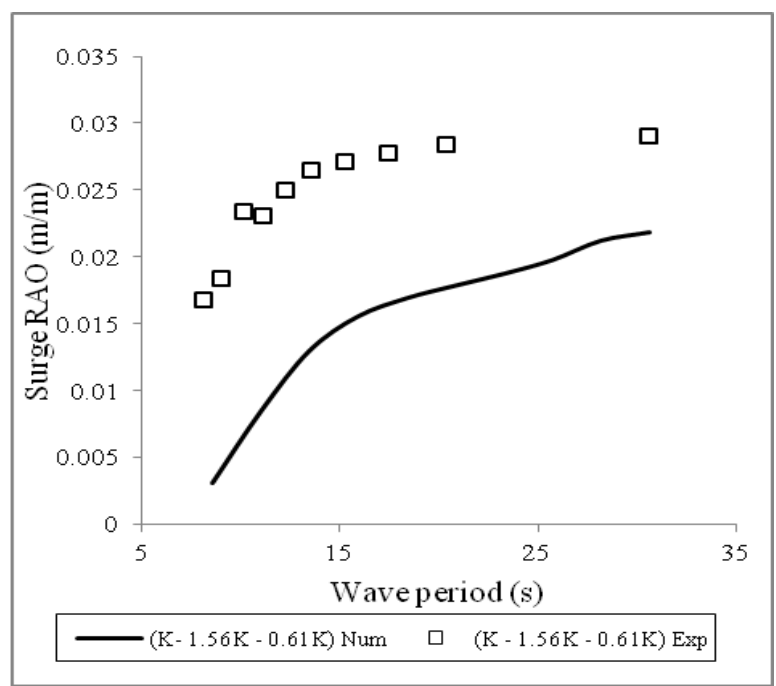

(d)

Fig. 12: Comparison of RAOs for TLP and TBTLP (with mooring to TB) (a) Surge RAO (b) Heave RAO (c) pitch RAO (d) TB- surge RAO

\section{Conclusion}

Experiments were conducted on a 1:150 scaled model of a Tension Based Tension Leg Platform (TBTLP) in regular waves and the dynamics of this new concept has been studied. This is the first ever experiments that have been reported on this new concept. Numerical modeling using ANSYS ${ }^{\circ}$ AQWA ${ }^{\text {TM }}$ software has been included for comparisons. The responses in the surge, heave and pitch dof of the TBTLP are compared with that of the TLPs in two different water depths. It has been observed that significant coupling and dynamic amplification exists between the surge dof of Tension Base and the heave dof of TBTLP in the resonant regions. The experiments carried out on a TBTLP with moored Tension Base showed drastic reduction of this coupled behavior and dynamic amplification in these regions, bringing out the importance of mooring lines of the Tension Base. The efficacy of the moored Tension Base has been successfully demonstrated by comparisons of responses of TBTLP (in $450 \mathrm{~m}$ ) with TLPs (in $225 \mathrm{~m}, 450 \mathrm{~m}$ ). From the experimental study it is concluded that by the provision of a Tension Base the TLPs catering to a lower water depth can be extended to deeper water depths by the introduction of a moored Tension Base without any modifications of the hull. 


\section{References}

Abbott, P., Nygaard, C., Huang, E., Johnson, B., DSouza, R., Dove, P., and Datta, B., (1994): Tension Raft/Frame Reduces TLP Motions, Costs, Offshore Magazine, Penn Well Publication.

Joseph, A., Lalu Mangal and Precy Sara Gorge. (2009): Coupled Dynamic Response of Three-columned Mini TLP, Journal of Naval Architecture and Marine Engineering, Vol. 6, No. 2, pp. 52-61. http://dx.doi.org/10.3329/jname.v6i2.2789

ANSYS, Inc., (2011): Known Issues and Limitations, Release 14.0, November.

AQWA (LINE, LIBRIUM and NAUT) manuals, (2010): Ansys Inc. Release 13.0, October.

Bhaskara Rao, D. S., Panneer Selvam, R. and Nagan Srinivasan, (2012): Hydrodynamic Analysis of Tension Based Tension Leg Platform, International Conference on Offshore Mechanics and Arctic Engineering, Rio de Janeiro, Brazil. pp. 201-207. http://dx.doi.org/10.1115/OMAE2012-83256.

Chakrabarti, S. K. (1994): Physical Modeling of Offshore Structures, World Scientific, Singapore.

Chandrasekaran, S., Kumar, D. and Ramanathan, R. (2013): Dynamic Response of Tension Leg Platform with Tuned Mass Dampers, Journal of Naval Arch and Marine Engineering, Vol. 10, No. 2, pp. 149-156. http://dx.doi.org/10.3329/jname.v10i2.16184

Jagannathan, S. K., (1992): The Suspended Tension Leg Platform (STLP): A New Platform Concept for Deepwater Exploration and Production, International Conference on Offshore Mechanics and Arctic Engineering, Calgary, Canada, pp 517-525.

John, M., Chan, K., Yang, Wooseuk, Y., Partha, K., and Jun Zou. (2009): An Extended Tension Leg Platform Design for Post-Katrina Gulf of Mexico, Proceedings of the Nineteenth International Offshore and Polar Engineering Conference, Osaka, Japan.

Kibbee, S., (1996): Sea Star Minimal Platform for Small Deepwater Reserves, Offshore Magazine.46-73.

Li, R., Gu, Y. and Bao, Y. (2000): A Study On Mini Tension Leg Platform For Marginal Oil Fields In Medium Water, Proceedings of the Tenth International Offshore and Polar Engineering Conference, Seattle, USA, 290 294.

Nagan, S., (1995): Tension Base TLP Can Support Development in 4,000 ft Depths, Offshore Magazine, Pennwell Publications.

Nagan, S. (2010): Tension - Based Tension Leg Platform: Technologies for Ultra Deepwater Applications, International Conference on Offshore Mechanics and Arctic Engineering, Shanghai, China. pp. 31-42. http://dx.doi.org/10.1115/OMAE2010-20042

Nagan, S. (2011): TLP for Gulf of Mexico Ultra Deep Water, Deep Offshore Technology International, New Orleans, USA.

Niedzwecki, J. M., Liagre, P. F., Roesset, J. M. and Kim, M. H. (2001): An Experimental Research Study of a Mini TLP, Proceedings of the Eleventh International Offshore and Polar Engineering Conference, Stavanger, Norway, pp 631- 634.

Sreekumar, S. (2001): Analytical and Experimental Investigations on the Dynamics Of Deep Water Mini Tension Leg Platform, IIT Madras, India.

Srinivasan, N. (1998): Tension Base for Tension Leg Platform, United States Patent No: 5707178. 